\title{
UTILIZAÇÃO DA DVA PARA ANÁLISE DA EVOLUÇÃO \\ DA RIQUEZA SETORIAL GERADA PELAS EMPRESAS LISTADAS NA BM\&FBOVESPA E DISTRIBUÍDA AOS SÓCIOS \\ E ACIONISTAS DURANTE OS MANDATOS PRESIDENCIAIS DE LULA (2007 - 2010) E DILMA (2011 - 2014)
}

\author{
USE OF DVA FOR ANALYSIS OF THE SECTORAL WEALTH \\ EVOLUTION GENERATED BY THE COMPANIES LISTED ON \\ THE BM\&FBOVESPA AND DISTRIBUTED TO MEMBERS AND \\ SHAREHOLDERS DURING THE PRESIDENTIAL MANDATES \\ OF LULA (2007 - 2010) AND DILMA (2011 - 2014)
}

Sirlene Koprowski ${ }^{1}$

Lara Fabiana Dallabona ${ }^{2}$ Gabriela Ramos de Oliveira ${ }^{3}$ Ana Rita Venzon Fernandes ${ }^{4}$ Marilei Kroetz ${ }^{5}$

1

Graduada em Ciências Contábeis pela UDEsc. Mestranda em Ciências Contábeis e Administração pela Unochapecó. Email: sirlene_sib@hotmail.com

\section{2}

Doutora em Ciências Contábeis e Administração pela FUrb. Professora da Universidade do Estado de Santa Catarina - udEsc. Email: lara. dallabona@udesc.br

3 Graduanda em Ciências Contábeis pela UDESC. Bolsista de Pesquisa na uDEsc/Ibirama. Email: ramoosg@outlook.com

4 Graduanda em Ciências Contábeis pela udEsc. Bolsista de Pesquisa na uDEsc/Ibirama. Email: anaritav.f@hotmail.com

5

Doutoranda em Economia no Instituto Superior de Economia e Gestão da Universidade de Lisboa/ Portugal. Professora da Universidade do Estado de Santa Catarina UDESC. Email: marilei. kroetz@udesc.br
RESUMO: O estudo objetivou utilizar a DvA para análise da evolução da riqueza setorial gerada pelas empresas listadas na BM\&FBovespa e distribuída aos sócios e acionistas, admitindo como período os mandatos presidenciais de Lula (2007-2010) e Dilma (2011-2014). Realizou-se a coleta e análise das DVAs de 169 empresas listadas na BM\&FBovespa e constantes em nove setores econômicos. A pesquisa classifica-se como descritiva, documental e quantitativa. Os resultados demonstraram que durante o governo Lula, seis setores obtiveram a maior distribuição de riqueza para Capitais Próprios no ano de 2010, último ano de governo. Ou seja, percebe-se uma evolução, em sua maioria, crescente no decorrer do referido mandato. Já no mandato de Dilma, quatro setores apresentaram o maior valor de distribuição para os sócios em 2011 (primeiro ano de governo), dois segmentos tiveram este resultado em 2013 e três em 2014. O estudo pretende contribuir com o meio acadêmico, com pesquisas que utilizam a DVA, em relação a sua vertente de distribuição de riqueza aos entes formadores, principalmente os sócios e acionistas, em empresas listadas na BM\&FBovespa, possibilitando uma análise dos dados a partir de mandatos presidenciais.

Palavras-chave: Demonstração de Valor Adicionado; Capitais Próprios; Lula. Dilma.

ABstract: The study aimed to use the DVA to analyze the evolution of the sectoral wealth generated by the companies listed on the BM\&FBovespa and distributed to shareholders and shareholders, admitting as a period the presidential mandates of Lula (2007-2010) and Dilma (2011-2014). The vars of 169 companies listed on the BM\&FBovespa were collected and analyzed in nine economic sectors. The research is classified as descriptive, documentary and quantitative. The results showed that during the Lula administration, six sectors obtained the largest distribution of wealth for Equity in 2010, the last year of government. That is to say, it is possible to see an evolution, for the most part, increasing during the said term. In Dilma's term, four sectors had the highest distribution value for members in 2011 (first year of government), two segments had this result in 2013 and three in 2014. The study aims to contrib- 
ute to the academic environment, with research that use the DVA, in relation to its wealth distribution aspect to the formation entities, mainly shareholders and shareholders, in companies listed on the BM\&FBovespa, making it possible to analyze the data from presidential mandatesf Value Added; Own capitals; Lula. Dilma.

KEYwORDS: Value Added Demonstration; Own capitals; Lula. Dilma.

\section{INTRODUÇÃO}

Com as constantes alterações diante à adoção às normas internacionais, os órgãos de regulamentação e os órgãos de classe profissionais surgem como pacificadores nesse processo de evidenciação de informações, criando padrões e metodologias mínimas de evidenciação que garantam um adequado nível de informações aos tomadores de decisões e aos demais interessados nas informações econômicas, financeiras e sociais das empresas (QUINTEIRO, 2004).

Desta forma emerge a evidenciação compulsória que denota àquelas informações exigidas por leis, normas, regulamentos, instruções, e outras das quais exigem certas informações a serem evidenciadas pelas empresas ao mercado (verrecchia, 2001). Porém, há de se considerar que informações voluntárias estão diretamente relacionadas com informações obrigatórias, visto o relevante papel social das organizações para com os seus investidores, acionistas e demais interessados.

Na perspectiva da divulgação, e considerando os demonstrativos apresentados pelas empresas, têm-se o Balanço social, e uma das vertentes do Balanço Social é a Demonstração de Valor Adicionado - DvA. Segundo Fagundes et al. (2008) o objetivo da DVA é apresentar o desempenho econômico da entidade e sua relação com a sociedade, além de mensurar o valor adicionado nos bens e serviços, durante o processo produtivo da empresa e a forma de distribuição deste, aos grupos que contribuíram para sua formação.

A obrigatoriedade da elaboração e divulgação da Demonstração de Valor Adicionado deu-se após a publicação da Lei nº 11.638 de 2007, que alterou o inciso " $V$ " no artigo 176 da Lei no 6.404/76, também chamada Lei das Sociedades Anônimas, tornando obrigatória essa demonstração contábil a partir do exercício de 2008, para as companhias de capital aberto no Brasil (ALMEIDA; SILVA, 2014).

Conforme Costa et al. (2013) por meio da DVA, é possível ter uma visão bem abrangente sobre a efetiva capacidade de uma empresa em gerar riqueza, ao agregar valor em seu patrimônio e o modo como se dá esta distribuição da riqueza entre os entes de produção. Dessa forma, a distribuição do valor agregado atenderá a quem usufrui da renda, ou seja, aos sócios, acionistas e financiadores externos, pela concessão do capital; os empregados, remunerados pela sua força de trabalho por meio de salários e encargos; e governo, com o pagamento de impostos municipais, estaduais ou federais.

Para Oliveira e Alves (2003) os dados apresentados pela DVA possuem grande relevância para a gestão governamental, nas esferas 
municipal, estadual ou federal, especialmente quanto à alocação de recursos e na busca de soluções para os crescentes problemas sociais, característicos de países em desenvolvimento, como o caso do Brasil. Desse modo, em análise à DVA, é possível identificar qual a efetiva contribuição da empresa para a sociedade, avaliando seu desempenho no contexto regional, ou seja, sua participação no desenvolvimento na comunidade onde está localizada. Também, por meio dessa demonstração, os órgãos públicos podem ter o amparo necessário, na decisão de conceder, continuar ou sessar subsídios e incentivos governamentais.

Cunha et al. (2005) complementam ainda, referenciando a DVA como um demonstrativo contábil que apresenta alguns benefícios oferecidos pela empresa à sociedade, como por exemplo, empregos para a comunidade onde a companhia está localizada; contribuição da empresa para o desenvolvimento econômico, por meio da sua capacidade de geração de riqueza; além disso, por meio da DVA, é possível identificar a própria riqueza gerada pela empresa, o valor recebido em transferência.

Em relação aos usuários, pode-se afirmar que a DvA, com seus dados socioeconômicos, atinge um vasto e diversificado número de grupos de interessados, ambos com os mais diferentes objetivos. Os investidores, por exemplo, aplicam recursos na empresa com o intuito de auferir rendimentos de seus investimentos (OLIVEIRA; ALVES, 2003). Para Ricarte (2005) estes usuários, também chamados de acionistas ou proprietários, formam a parcela de capital próprio da entidade e por meio da DVA, retiram informações referentes à fatia da riqueza criada em certo período para este ente, análise geral do investimento, a viabilidade de continuar ou não aplicando recursos na empresa bem como, a análise global do empreendimento e sua saúde econômica.

A remuneração de capitais próprios, segundo Cosenza (2003), se dá principalmente, por meio do pagamento de dividendos ou juros sobre capitais próprios. Esta destinação aos proprietários pode gerar certo conflito, entre distribuir a riqueza para os investidores ou retê-la para investimentos futuros na companhia, visto que o resultado de tal decisão poderá influenciar na taxa de atratividade do negócio. Há entendimentos que, essa parcela retida para reinvestimento, ou seja, os lucros retidos devem também ser inclusos neste grupo, pois de certa forma, pertencem aos sócios e acionistas. No entanto, na DVA, o indicado é que esse valor seja apresentado em tópico separado dos demais itens, para facilitar a compreensão dos usuários externos à entidade.

Desta forma, o estudo pretende responder ao seguinte questionamento: As variações na distribuição de riqueza para capital próprio das empresas listadas na BMEFBovespa convergem ou divergem entre os mandatos presidenciais do governo Lula e Dilma? Consequentemente objetiva-se analisar se as variações na distribuição de riqueza para capital próprio das empresas listadas na BM\&F Bovespa convergem ou divergem entre os mandatos presidenciais do governo Lula (20072010) e Dilma (2011-2014). 
Pode-se inferir que as empresas participantes do estudo terão uma visão abrangente da evolução desses dados econômico-financeiros durante os períodos presidenciais em análise. Da mesma forma, os outros entes envolvidos na distribuição de riqueza, pesquisadores e a sociedade em geral, poderão utilizar tais bases para as mais diversas comparações. Assim sendo, as análises e resultados obtidos, podem gerar oportunidades para novas pesquisas.

\section{REVISÃO DA LITERATURA}

Nesta seção abordam-se os temas Demonstração de Valor Adicionado e a distribuição de valor adicionado aos sócios e acionistas, por representar um importante ente participante na formação da riqueza da empresa, em decorrência do investimento de capital próprio na organização, constituindo uma base teórica fundamental para o entendimento deste trabalho.

Em dezembro de 2007, com a aprovação da Lei 11.638/07, pelo Congresso Nacional e posteriormente sancionada pela Presidência da República, pode-se notar a evolução das práticas contábeis no Brasil, ao dar sequência ao processo de convergência às Normas Internacionais de Contabilidade. A referida Lei alterou vários dispositivos contábeis previstos na Lei 6.404/76 (costA et al., 2013).

Sendo criado a partir da Resolução CFC n. ${ }^{\circ}$ 1.055/05, desde então, O CPC vem promovendo a harmonização das Normas Brasileiras às Normas Internacionais de Contabilidade, especialmente a IAS e IFRS (International Accounting Standard e International Financial Reporting Standard). No entanto, nota-se que a contabilidade brasileira, mediante os pronunciamentos técnicos emitidos pelo CPC, possui alguns pontos diferenciados em comparação às IAs e IFRs, com conteúdo que ultrapassam as exigências impostas internacionalmente (CARMO et al., 2011).

Dentre essas peculiaridades das Normas Brasileiras em relação às IAS e IFRs, Almeida e Silva (2014) destacam relevante na evolução das práticas contábeis no Brasil, o Pronunciamento Técnico CPC o9 que trata da Demonstração de Valor Adicionado, que rege sobre a elaboração e a divulgação da respectiva demonstração. Este pronunciamento é um dos poucos que não possui uma norma internacional equivalente, e está vinculado ao balanço social, considerando a harmonização das normas contábeis, isso acaba por possibilitar que os órgãos contábeis brasileiros, contribuam efetivamente para o processo de normatização contábil internacional.

Segundo Costa et al. (2013), o balanço Social é direcionado a analisar a relação da empresa com seus empregados, alguns dados são extremamente relevantes e precisam compor as informações constantes neste demonstrativo, tais como: dados de emprego, relações de trabalho encontradas na companhia, a maneira como os trabalhadores ingressam no mercado de trabalho e sua evolução no decorrer do tempo, investimentos em formação e desenvolvimento profissional, remunerações e demais benefícios concedidos aos em- 
pregados, condições de higiene e segurança, além de outras condições de trabalho.

Porém a DVA é mais popular e antiga do que o Balanço Social, surgindo inicialmente na Europa há vários anos, principalmente por influências de países como Inglaterra, França e Alemanha. No decorrer dos anos, a DVA começou a ser cada vez mais conhecida internacionalmente, até mesmo a oNU - Organização das Nações Unidas passou a recomendar a elaboração e divulgação desse demonstrativo (costa et al., 2013).

Cosenza (2003) expõe que a Demonstração de Valor Adicionado, deve ter como objetivo, o repasse de informações sobre tal processo, de modo simples e objetivo, para que qualquer usuário consiga compreender, sendo ele conhecedor da área contábil ou não. Em relação aos usuários, pode-se afirmar que a DvA, com seus dados socioeconômicos, atinge um vasto e diversificado número de grupos de interessados, ambos com os mais diferentes objetivos. Os investidores, por exemplo, aplicam recursos na empresa com o intuito de auferir rendimentos de seus investimentos (OLIVEIRA; ALVES, 2003).

Para Ricarte (2005) estes usuários, também chamados de acionistas ou proprietários, formam a parcela de capital próprio e por meio da DVA, retiram informações referentes à fatia da riqueza criada em certo período para este ente, análise geral do investimento, a viabilidade de continuar ou não aplicando recursos na empresa bem como, a análise global do empreendimento e sua saúde econômica. Paralelamente, os administradores das companhias também utilizam esta demonstração como uma ferramenta de suporte ao planejamento estratégico e na tomada de decisão, relacionada à gestão e controle da organização, além de identificarem a parcela de valor adicionado que lhes deve ser destinada ao final do exercício.

O quarto ente de distribuição apresentado pelo CPC o9 é o item "remuneração de capitais próprios". Borinelli e Pimentel (2010) afirmam que este item se refere à remuneração devida aos sócios e acionistas, em função do capital investido na organização. Assim, Ricarte (2005) comenta que os sócios e acionistas participam da distribuição de valor adicionado, justamente por este motivo, por contribuírem com seu capital próprio nas atividades produtivas da empresa. Para Vieira (2009) a informação da parcela de riqueza destinada aos sócios e acionistas em determinado período, possibilita uma análise do investimento, avaliando o retorno efetivo sobre o capital investido e servindo como parâmetro para um possível redirecionamento de recursos.

\section{ASPECTOS METODOLÓGICOS}

A pesquisa caracteriza-se como quantitativa, descritiva e documental, sendo que, a fonte documental utilizada foram as demonstrações de valor adicionado das empresas com ações na BM\&FBovespa, exceto as empresas que possuíam a data de registro na CVM posterior à 2007, empresas do setor financeiro e outros; e as que não possuíam os 
dados suficientes para análise. A coleta de dados iniciou-se, com a consulta no site da Bovespa (www.bmfbovespa.com.br), das datas de registros na cvm das 501 (quinhentas e uma) empresas listadas e pertencentes aos dez segmentos econômicos, classificados pela BM\&FBovespa.

Tais dados foram coletados entre os dias 20 a 29 do mês de março do ano de 2016. Com 285 (duzentas e oitenta e cinco) empresas, iniciou-se a coleta das DVA's no site da Bovespa (www.bmfbovespa. com.br). Tal etapa foi realizada entre os dias 30 de março a 23 de abril de 2016 e todas as demonstrações foram organizadas em planilhas eletrônicas do Microsoft Excel.

O período para análise ficou definido entre os anos de 2007 a 2014, ou seja, o $2^{-}$mandato do governo Lula (2007 a 2010) e o $1^{\underline{0}}$ mandato do governo Dilma (2011 a 2014). A amostra final é composta de 169 (cento e sessenta e nove) empresas que disponibilizaram todos os dados necessários para o estudo. Para apresentação dos resultados, o estudo fez uso da estatística descritiva, por meio de percentuais que evidenciaram a evolução anual da remuneração para capital próprio no decorrer do tempo em análise, além de tabelas que demonstraram o montante distribuído para tal ente por ano e por governo, assim como os referidos percentuais de evolução anuais.

\section{DESCRIÇÃO E ANÁLISE DOS DADOS}

Os dados expostos na Tabela 1 referem-se à distribuição de valor adicionado para Remuneração de Capitais Próprios, que segundo o Pronunciamento Técnico CPC 09 - Demonstração de Valor Adicionado são "valores relativos à remuneração atribuída aos sócios e acionistas".

Trata-se então, de um ente de grande relevância neste estudo, já que aponta diretamente o retorno que a empresa está trazendo aos seus responsáveis. As informações foram retiradas das demonstrações das empresas pertencentes aos cinco setores econômicos inicialmente abordados: Bens Industriais; Construção e Transporte; Consumo Cíclico; Consumo não Cíclico e Materiais Básicos. Este componente da distribuição de valor adicionado divide-se entre os itens Juros sobre Capital Próprio, Dividendos, Lucros Retidos/Prejuízos do Exercício, Participações dos não-controladores nos lucros retidos e o item "sem descrição", que abrange os casos de empresas que não divulgaram detalhadamente a destinação de valor entre tais subcontas.

O período de análise permaneceu inalterado, sendo de 2007 a 2010, correspondente ao governo Lula e de 2011 a 2014, ao mandato presidencial de Dilma. Para melhor comparação entre os períodos, mantiveram-se os percentuais de evolução, calculados sempre considerando o ano de referência em relação ao anterior imediato, exceto nos comparativos feitos entre os anos 2007/2010 e 2011/2014.

Tendo como base os dados dispostos na Tabela 1, analisou-se como foi destinada a parcela pertencente aos sócios e acionistas, denominada Remuneração de Capitais Próprios, considerando as empresas dos cinco segmentos econômicos, abordados inicialmente. No setor de 
Bens Industriais, perceberam-se acréscimos durante todo o governo Lula, nos juros sobre capital próprio, com índices de 13,41\% em 2008, $13,90 \%$ e $17,48 \%$ nos dois períodos seguintes.

Enquanto isso, os dividendos e os lucros retidos, apresentaram saltos consideráveis em 2008 de $111,50 \%$ e $60,31 \%$ respectivamente, ao passo que em 2009, o primeiro item teve seu valor reduzido à distribuição de riqueza que tinha em 2007 e no ano seguinte, caiu $68,58 \%$ em relação a este último valor. Da mesma forma, os lucros retidos tiveram decréscimos de 10,99\% em 2009 e 25,89\% em 2010. As participações dos não-controladores apresentaram uma pequena redução de 3,28\% em 2008, uma melhora de 8,75\% em 2009 e aumentaram significativamente em 2010, com percentual de 51,43\%. O item "sem descrição" permaneceu durante todo o período de mandato, sem valores, o que se pode concluir que as empresas neste período detalharam corretamente os valores entre os itens que compõem tal componente da distribuição. (TABELA 1)

Durante o segundo mandato presidencial analisado, no setor de Bens Industriais, os percentuais de evolução apresentaram-se distintos entre os itens de análise, sendo necessário o destaque para cada um desses componentes. Nos juros sobre capital próprio, por exemplo, foi possível perceber nos dois primeiros anos, aumentos de $1,08 \%$ e 13,24\%, enquanto nos dois últimos, reduções de 4,29\% e 1,05\%, ou seja, os valores não passaram por significativas variâncias. Este item, de acordo com Iudícibus et al. (2010) e observado o CPC 09 (2008), inclui valores devidos aos sócios e acionistas referente aos juros sobre o resultado do período.

Presume-se assim, que os percentuais de evolução dos juros sobre capital próprio, acompanhem o histórico dos resultados dos exercícios sociais analisados. Os dividendos tiveram reduções de 2011 a 2013, com índices de 0,99\%, 27,87\% e 0,95\%, sendo que em 2014, apresentaram uma melhora, mesmo assim, fecharam com um valor abaixo do início do período. Da mesma forma, os lucros retidos iniciaram com um percentual negativo de $17,56 \%$, seguiram para 2012 e 2013, com acréscimos de $24,89 \%$ e $8,78 \%$ e voltaram a reduzir em 2014 , com $17,54 \%$.

As participações dos não-controladores também apresentaram quedas em seu histórico, com 6,58\% em 2011 e 73,67\% em 2012, ao passo que em 2013, mesmo ficando abaixo da faixa que estavam em 2011, demonstraram uma recuperação no valor, seguindo para 2014 com redução novamente de 16,06\%. Já o item "sem descrição", que no mandato anterior manteve-se zerado, apresentou um salto relevante em 2012, passando de $\mathrm{R} \$ 171.254,00$ em 2011 para $\mathrm{R} \$ 699.008$, oo e nos períodos posteriores continuou com aumentos, de 12,50\% em 2013 e 5,11\% em 2014.

Construção e Transporte foi um setor que, durante o governo Lula, demonstrou várias oscilações nos índices dos itens que formam a Remuneração de Capitais Próprios. Em 2008, pode-se perceber um salto no valor dos juros sobre capitais próprios, enquanto em 2009 
Revista de Gestão Pública

PRÁTICAS E DESAFIOS

ISSN: 2177-1243

TABela 1 - Distribuição da riqueza para Capital Próprio

\begin{tabular}{|c|c|c|c|c|c|c|c|c|c|c|c|c|c|}
\hline SETOR & GOVERNO & ANO & JuROS S/ C.P. & $\%$ & DIVIDENDOS & $\%$ & $\begin{array}{l}\text { LUCROS } \\
\text { RETIDOS }\end{array}$ & $\%$ & $\begin{array}{l}\text { PARt. Ñ } \\
\text { CONTROL. }\end{array}$ & $\%$ & $\begin{array}{c}\text { SEM } \\
\text { DESCRIÇÃo }\end{array}$ & $\%$ & TOTAL CP \\
\hline \multirow{12}{*}{ 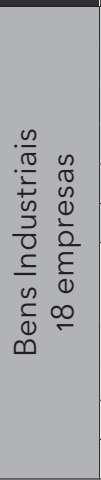 } & \multirow{4}{*}{$\begin{array}{l}\text { Governo } \\
\text { Lula }\end{array}$} & 2007 & $4.700 .340,00$ & - & $1.527 \cdot 372,00$ & - & $13.915 .991,00$ & - & $90.887,00$ & - & $\mathrm{O}, \mathrm{OO}$ & - & $20.234 \cdot 590,00$ \\
\hline & & 2008 & $5.330 .837,00$ & 13,41 & $3.230 .388,00$ & 111,50 & $22.309 .088,00$ & 60,31 & $87.905,00$ & $-3,28$ & 0,00 & 0,00 & $30.958 .218,00$ \\
\hline & & 2009 & $6.071 .916,00$ & 13,90 & $1.764 .053,00$ & $-45,39$ & $19.857 .818,00$ & $-10,99$ & $95 \cdot 595,00$ & 8,75 & 0,00 & 0,00 & $27 \cdot 789 \cdot 382,00$ \\
\hline & & 2010 & $7.133 .466,00$ & 17,48 & $554.246,00$ & $-68,58$ & $14.715 .788,00$ & $-25,89$ & $144.759,00$ & 51,43 & 0,00 & 0,00 & $22.548 .259,00$ \\
\hline & \multicolumn{2}{|c|}{$\% 2007 / 2010$} & & 51,76 & & $-63,71$ & & 5,75 & & 59,27 & & 0,00 & \\
\hline & \multicolumn{2}{|c|}{ Subtotal } & $23.236 .559,00$ & & $7.076 .059,00$ & & $70.798 .685,00$ & & $419.146,00$ & & 0,00 & & $101.530 .449,00$ \\
\hline & \multirow{4}{*}{$\begin{array}{c}\text { Governo } \\
\text { Dilma }\end{array}$} & 2011 & $7.210 .741,00$ & 1,08 & $548.769,00$ & $-0,99$ & $12.132 .262, \mathrm{OO}$ & $-17,56$ & $135.238,00$ & $-6,58$ & $171.254,00$ & 0,00 & $20.198 .264,00$ \\
\hline & & 2012 & $8.165 .457,00$ & 13,24 & $395.849,00$ & $-27,87$ & $15.151 .811,00$ & 24,89 & $35.607,00$ & $-73,67$ & $699.008,00$ & 308,17 & $24.447 .732,00$ \\
\hline & & 2013 & $7.815 .102,00$ & $-4,29$ & $392.104, \mathrm{OO}$ & $-0,95$ & $16.482 .795,00$ & 8,78 & $108.742,00$ & 205,40 & $786.410,00$ & 12,50 & $25.585 .153,00$ \\
\hline & & 2014 & $7 \cdot 733 \cdot 365,00$ & $-1,05$ & $536.747,00$ & 36,89 & $13 \cdot 592.226,00$ & $-17,54$ & $91.279,00$ & $-16,06$ & $826.600,00$ & 5,11 & $22.780 .217,00$ \\
\hline & \multicolumn{2}{|c|}{$\% 2011 / 2014$} & & 7,25 & & $-2,19$ & & 12,03 & & $-32,50$ & & 382,67 & \\
\hline & \multicolumn{2}{|l|}{ Subtotal } & $30.924 .665,00$ & & $1.873 .469,00$ & & $57.359 .094,00$ & & $370.866,00$ & & $2.483 .272,00$ & & $93.011 .366,00$ \\
\hline \multirow{12}{*}{ 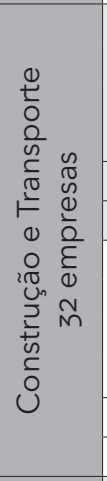 } & \multirow{4}{*}{$\begin{array}{c}\text { Governo } \\
\text { Lula }\end{array}$} & 2007 & $137.935,00$ & - & $1.688 .936,00$ & - & $-19.362 .738,00$ & - & $12.555,00$ & - & 0,00 & - & $-17 \cdot 523 \cdot 312,00$ \\
\hline & & 2008 & $401.386,00$ & 191,00 & $1.354 .211,00$ & $-19,82$ & $-2.534 .774, \mathrm{oO}$ & $-86,91$ & $70.322,00$ & 460,11 & 0,00 & 0,00 & $-708.855,00$ \\
\hline & & 2009 & $107.211,00$ & $-73,29$ & $1.759 .059,00$ & 29,90 & $4.890 .336,00$ & $-292,93$ & $122.565,00$ & 74,29 & $188.224,00$ & 0,00 & $7.067 .395,00$ \\
\hline & & 2010 & $54.895,00$ & $-48,80$ & $1.516 .878, \mathrm{oO}$ & $-13,77$ & $-20.215 .680,00$ & $-513,38$ & $114.128,00$ & $-6,88$ & $50.873,00$ & $-72,97$ & $-18.478 .906,00$ \\
\hline & \multicolumn{2}{|c|}{$\% 2007 / 2010$} & & $-60,20$ & & $-10,19$ & & 4,41 & & 809,02 & & 100,00 & \\
\hline & \multicolumn{2}{|c|}{ Subtotal } & $701.427,00$ & & $6.319 .084,00$ & & $-37.222 .856,00$ & & $319.570,00$ & & $239.097,00$ & & $-29.643 .678,00$ \\
\hline & \multirow{4}{*}{$\begin{array}{c}\text { Governo } \\
\text { Dilma }\end{array}$} & 2011 & $121.361,00$ & 121,08 & $1.644 .655,00$ & 8,42 & $-1.628 .125, \mathrm{OO}$ & $-91,95$ & $94.669,00$ & $-17,05$ & $\mathrm{O}, \mathrm{OO}$ & $-100,00$ & $232.560,00$ \\
\hline & & 2012 & $146.673,00$ & 20,86 & $1.597 .628, \mathrm{oO}$ & $-2,86$ & $-1.705 .634,00$ & 4,76 & $82.139,00$ & $-13,24$ & $229.727,00$ & $\mathrm{O}, \mathrm{OO}$ & $350.533,00$ \\
\hline & & 2013 & $274.314,00$ & 87,02 & $2.363 .305,00$ & 47,93 & $1.665 .231,00$ & $-197,63$ & $319.564,00$ & 289,05 & 0,00 & $-100,00$ & $4.622 .414,00$ \\
\hline & & 2014 & $183.724,00$ & $-33,02$ & $1.846 .063,00$ & $-21,89$ & $-1.636 .391,00$ & $-198,27$ & $271.665,00$ & $-14,99$ & 0,00 & $\mathrm{O}, \mathrm{OO}$ & $665.061,00$ \\
\hline & \multicolumn{2}{|c|}{$\% 2011 / 2014$} & & 51,39 & & 12,25 & & 0,51 & & 186,96 & & 0,00 & \\
\hline & \multicolumn{2}{|c|}{ Subtotal } & $726.072,00$ & & $7.451 .651,00$ & & $-3.304 .919,00$ & & $768.037,00$ & & $229.727,00$ & & $5.870 .568,00$ \\
\hline \multirow{12}{*}{ 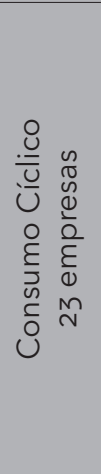 } & \multirow{4}{*}{$\begin{array}{c}\text { Governo } \\
\text { Lula }\end{array}$} & 2007 & $133.300,00$ & - & $275 \cdot 470,00$ & - & $76.357,00$ & - & $-388.068,00$ & - & $-14.364,00$ & - & $82.695,00$ \\
\hline & & 2008 & $153.060,00$ & 14,82 & $186.509,00$ & $-32,29$ & $688.718,00$ & 801,97 & $-225.115,00$ & $-41,99$ & $-14.399,00$ & 0,24 & $788.773,00$ \\
\hline & & 2009 & $144.826,00$ & $-5,38$ & $316.494,00$ & 69,69 & $373.339,00$ & $-45,79$ & $49.844,00$ & $-122,14$ & $\mathrm{O}, \mathrm{OO}$ & $-100,00$ & $884.503,00$ \\
\hline & & 2010 & $230.284,00$ & 59,01 & $467.899,00$ & 47,84 & $1.057 .794,00$ & 183,33 & $19.011,00$ & $-61,86$ & $29.523,00$ & 0,00 & $1.804 .511,00$ \\
\hline & \multicolumn{2}{|c|}{$\% 2007 / 2010$} & & 72,76 & & 69,85 & & $1.285,33$ & & $-104,90$ & & $-305,53$ & \\
\hline & \multicolumn{2}{|c|}{ Subtotal } & $661.470,00$ & & $1.246 .372,00$ & & $2.196 .208,00$ & & $-544 \cdot 328,00$ & & 760,00 & & $3.560 .482,00$ \\
\hline & \multirow{4}{*}{$\begin{array}{c}\text { Governo } \\
\text { Dilma }\end{array}$} & 2011 & $271.745,00$ & 18,00 & $655.298,00$ & 40,05 & $541.224,00$ & $-48,83$ & $-388.938,00$ & $-2.145,86$ & $\mathrm{O}, \mathrm{OO}$ & $-100,00$ & $1.079 .329,00$ \\
\hline & & 2012 & $316.652,00$ & 16,53 & $802.070,00$ & 22,40 & $1.034 .882,00$ & 91,21 & $-146.099,00$ & $-62,44$ & 0,00 & $\mathrm{O}, \mathrm{OO}$ & $2.007 \cdot 505,00$ \\
\hline & & 2013 & $435.850,00$ & 37,64 & $1.049 \cdot 541,00$ & 30,85 & $2.348 .019,00$ & 126,89 & $-2.280,00$ & $-98,44$ & $0, \mathrm{OO}$ & 0,00 & $3.831 .130,00$ \\
\hline & & 2014 & $432.957,00$ & $-0,66$ & $518.772,00$ & $-50,57$ & $2.970 .369,00$ & 26,51 & $-84.296,00$ & $3.597,19$ & $0, \mathrm{OO}$ & 0,00 & $3.837 .802,00$ \\
\hline & \multicolumn{2}{|c|}{$\% 2011 / 2014$} & & 59,32 & & $-20,83$ & & 448,82 & & $-78,33$ & & 0,00 & \\
\hline & \multicolumn{2}{|l|}{ Subtotal } & $1.457 .204,00$ & & $3.025 .681,00$ & & $6.894 .494,00$ & & $-621.613,00$ & & $\mathrm{O}, \mathrm{OO}$ & & $10.755 .766,00$ \\
\hline
\end{tabular}




\section{Revista de Gestão Pública}

PRÁTICAS E DESAFIOS

ISSN: 2177-1243

\begin{tabular}{|c|c|c|c|c|c|c|c|c|c|c|c|c|c|}
\hline \multirow{12}{*}{ 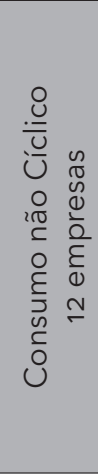 } & \multirow{4}{*}{$\begin{array}{l}\text { Governo } \\
\text { Lula }\end{array}$} & 2007 & $163.897,00$ & - & $486.066,00$ & - & $580.853,00$ & - & $5 \cdot 324,00$ & - & 0,00 & - & $1.236 .140,00$ \\
\hline & & 2008 & $186.430,00$ & 13,75 & $569.181,00$ & 17,10 & $343.044,00$ & $-40,94$ & $3.122,00$ & $-41,36$ & 0,00 & 0,00 & $1.101 .777,00$ \\
\hline & & 2009 & $212.908,00$ & 14,20 & $497 \cdot 455,00$ & $-12,60$ & $1.196 .042,00$ & 248,66 & 138,00 & $-95,58$ & $\mathrm{O}, \mathrm{OO}$ & 0,00 & $1.906 .543,00$ \\
\hline & & 2010 & $452.810,00$ & 112,68 & $273.846,00$ & $-44,95$ & $1.483 .493,00$ & 24,03 & $-27 \cdot 739,00$ & $-20.200,72$ & $744.050,00$ & 0,00 & $2.926 .460,00$ \\
\hline & \multicolumn{2}{|c|}{$\% 2007 / 2010$} & & 176,28 & & $-43,66$ & & 155,40 & & $-621,02$ & & 0,00 & \\
\hline & \multicolumn{2}{|c|}{ Subtotal } & $1.016 .045,00$ & & $1.826 .548,00$ & & $3.603 .432,00$ & & $-19.155,00$ & & $744.050,00$ & & $7.170 .920,00$ \\
\hline & \multirow{4}{*}{$\begin{array}{l}\text { Governo } \\
\text { Dilma }\end{array}$} & 2011 & $817.813,00$ & 80,61 & $296.387,00$ & 8,23 & $1.593 .413,00$ & 7,41 & $3.636,00$ & $-113,11$ & $830.901,00$ & 11,67 & $3 \cdot 542.150,00$ \\
\hline & & 2012 & $459.395,00$ & $-43,83$ & $399.993,00$ & 34,96 & $1.679 \cdot 356,00$ & 5,39 & $119.095,00$ & $3.175,44$ & $861.222,00$ & 3,65 & $3.519 .061,00$ \\
\hline & & 2013 & $915.530,00$ & 99,29 & $410.686,00$ & 2,67 & $1.597 \cdot 373,00$ & $-4,88$ & $352.465,00$ & 195,95 & $847.806,00$ & $-1,56$ & $4.123 .860,00$ \\
\hline & & 2014 & $981.568,00$ & 7,21 & $581.111,00$ & 41,50 & $2.703 .007,00$ & 69,22 & $496.007,00$ & 40,73 & $741.221,00$ & $-12,57$ & $5.502 .914,00$ \\
\hline & \multicolumn{2}{|c|}{$\% 2011 / 2014$} & & 20,02 & & 96,06 & & 69,64 & & $13.541,56$ & & $-10,79$ & \\
\hline & \multicolumn{2}{|c|}{ Subtotal } & $3 \cdot 174 \cdot 306,00$ & & $1.688 .177,00$ & & $7 \cdot 573.149,00$ & & $971.203,00$ & & $3.281 .150,00$ & & $16.687 .985,00$ \\
\hline \multirow{12}{*}{ 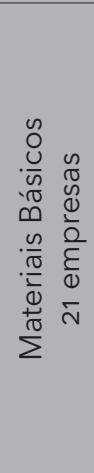 } & \multirow{4}{*}{$\begin{array}{l}\text { Governo } \\
\text { Lula }\end{array}$} & 2007 & $1.454 .606,00$ & - & $2.156 .964,00$ & - & $26.637 .580,00$ & - & $2.162 .551,00$ & - & 0,00 & - & $32.411 .701,00$ \\
\hline & & 2008 & $1.114 .403,00$ & $-23,39$ & $1.933 .002,00$ & $-10,38$ & $21.579 \cdot 479,00$ & $-18,99$ & $916.325,00$ & $-57,63$ & 0,00 & 0,00 & $25 \cdot 543.209,00$ \\
\hline & & 2009 & $1.035 .794,00$ & $-7,05$ & $1.777 .895,00$ & $-8,02$ & $14.108 .726,00$ & $-34,62$ & $728.249,00$ & $-20,53$ & 0,00 & 0,00 & $17.650 .664,00$ \\
\hline & & 2010 & $1.250 .641,00$ & 20,74 & $2.149 \cdot 370,00$ & 20,89 & $35.251 .267,00$ & 149,85 & $897.660,00$ & 23,26 & 0,00 & 0,00 & $39.548 .938, \mathrm{oo}$ \\
\hline & \multicolumn{2}{|c|}{$\% 2007 / 2010$} & & $-14,02$ & & $-0,35$ & & 32,34 & & $-58,49$ & & 0,00 & \\
\hline & \multicolumn{2}{|c|}{ Subtotal } & $4.855 .444,00$ & & $8.017 .231,00$ & & $97 \cdot 577.052,00$ & & $4 \cdot 704.785,00$ & & $\mathrm{O}, \mathrm{OO}$ & & $115.154 .512,00$ \\
\hline & \multirow{4}{*}{$\begin{array}{c}\text { Governo } \\
\text { Dilma }\end{array}$} & 2011 & $272.581, \mathrm{OO}$ & $-78,20$ & $1.070 .593,00$ & $-50,19$ & $39.596 .151,00$ & 12,33 & $-266.995,00$ & $-129,74$ & $-32.601,00$ & $0, \mathrm{OO}$ & $40.639 .729,00$ \\
\hline & & 2012 & $47.129,00$ & $-82,71$ & $280.823,00$ & $-73,77$ & $7.145 \cdot 337,00$ & $-81,95$ & $-587.466,00$ & 120,03 & $-148.897,00$ & 356,73 & $6.736 .926,00$ \\
\hline & & 2013 & $253.430,00$ & 437,74 & $874.367,00$ & 211,36 & $-287.848, \mathrm{oO}$ & $-104,03$ & $-349.647,00$ & $-40,48$ & $-137.260,00$ & $-7,82$ & $353.042,00$ \\
\hline & & 2014 & $26.597,00$ & $-89,51$ & $315 \cdot 376,00$ & $-63,93$ & $2.378 .875,00$ & $-926,43$ & $-975.033,00$ & 178,86 & $-44 \cdot 355,00$ & $-67,69$ & $1.701 .460,00$ \\
\hline & \multicolumn{2}{|c|}{$\% 2011 / 2014$} & & $-90,24$ & & $-70,54$ & & $-93,99$ & & 265,19 & & 36,05 & \\
\hline & \multicolumn{2}{|c|}{ Subtotal } & $599 \cdot 737,00$ & & $2.541 .159,00$ & & $48.832 .515,00$ & & $-2.179 .141,00$ & & $-363.113,00$ & & $49 \cdot 431.157,00$ \\
\hline
\end{tabular}

FONTE: Elaborado pela autora. 
retornou próximo ao valor que estava em 2007 e no último ano, apresentou queda de $48,80 \%$. Os dividendos tiveram redução em 2008 de $19,82 \%$, uma melhora de $29,90 \%$ no ano seguinte e queda novamente de $13,77 \%$ em 2010.

Os lucros retidos apresentaram nos anos de 2007, 2008 e 2010 valores negativos, o que se presume, que sejam prejuízos apurados no período, somente em 2009 foi identificado o valor positivo de R\$4.890.336,00. O resultado deste subitem acabou influenciando a distribuição total ao ente Remuneração de Capitais Próprios, que apresentou valor positivo também, somente em 2009. Follmann et al. (2011), identificaram um acréscimo na distribuição média da Dva neste setor do ano de 2008 para 2009, o que em partes assemelha-se aos achados neste estudo.

Silva (2010) identificou parcelas de valores positivos destinadas aos sócios, nos anos de 2007, 2008 e 2009. As participações dos não-controladores tiveram uma grande evolução em 2008, comparado ao valor do ano anterior, continuou com acréscimo em 2009, com um percentual de $74,29 \%$ e reduziram $6,88 \%$ no último ano de governo. O item "sem descrição" demonstrou valores destinados, apenas nos anos de 2009 e 2010.

Adiante, no segundo mandato presidencial analisado, o setor de Construção e Transporte apresentou as seguintes evoluções nos anos de 2011 e 2012, em alguns itens aqui citados: juros sobre capitais próprios teve um salto superior a $100 \%$ no primeiro ano, recuperando-se da redução de 2010 e continuou em alta em 2012, com 20,86\%; os dividendos aumentaram $8,42 \%$ em 2011 e reduziram 2,86\% no período posterior; e as participações dos não-controladores passaram por duas quedas de $17,05 \%$ em 2011 e 13,24\% em 2012.

Os lucros retidos, apenas em 2013 tiveram valor positivo de $\mathrm{R} \$$ 1.665.231,00, no restante do período presidencial em análise, apresentaram valores negativos, ou seja, prováveis prejuízos nos exercícios. Além disso, o item "sem descrição" teve valor distribuído apenas em 2012, nos demais anos, ficou zerado, ou seja, somente neste ano foram identificados casos de empresas que não detalharam a distribuição de riqueza, conforme preceitua o CPC o9 (2008).

Analisando o setor de Consumo Cíclico, no primeiro mandato presidencial em estudo, nota-se grande variância nas evoluções entre os itens que formam a distribuição para Capitais Próprios. Iniciando pelos juros sobre capitais próprios, percebe-se um acréscimo de $14,82 \%$ em 2008 em comparação a 2007, uma pequena redução de 5,38\% em 2009 e um aumento de 59,01\% em 2010.

Os dividendos passaram por uma queda de $32,29 \%$ em 2008 , seguida de aumentos nos dois períodos posteriores, de $69,69 \%$ e $47,84 \%$. Os lucros retidos demonstraram aumento na primeira comparação do período, passando de $\mathrm{R} \$ 76.357, \mathrm{Oo}$ em 2007 para $\mathrm{R} \$ 688.718$,oo no ano seguinte, porém em 2009, demonstraram um decréscimo de $45,79 \%$ nesse último valor e novamente em 2010, apresentaram uma grande evolução, chegando ao valor de R\$ 1.057.794,00. 
Conforme esclarecem Iudícibus et al. (2010), neste item estão inclusos valores correspondentes à parte do lucro do exercício destinada para constituição de reservas, valores de juros sobre capital próprio com este fim e ainda, conforme Santos (2007), as parcelas sem destinação específica podem também serem consideradas nesta subconta. As participações dos não-controladores nos dois primeiros anos desse mandato, demonstraram valores negativos de - $\mathrm{R} \$$ 388.068,00 em 2007 e - $\mathrm{R} \$ 225.115$,00 em 2008, enquanto nos dois períodos subsequentes, demonstraram valores distribuídos positivos de R\$ 49.844,00 e R\$19.011,00.

No governo Dilma, o setor de Consumo Cíclico apresentou, nos juros sobre capitais próprios e nos dividendos, evoluções positivas do período de 2011 a 2013, com os seguintes percentuais: no primeiro item os aumentos foram de 18,00\% em 2011, 16,53\% em 2012 e 37,64\% em 2013; e no segundo foram de 40,05\%, 22,40\% e 30,85\%, respectivamente. No ano de 2014, ambos tiveram reduções de 0,66\% e 50,57\%, respectivamente.

As empresas pertencentes ao setor de Consumo não Cíclico, também apresentaram percentuais evolutivos variados entre os itens que compõem a distribuição para Capitais Próprios durante o período presidencial de Lula. Por isso faz-se necessário o destaque de cada componente. Os juros sobre capitais próprios demonstraram aumentos de $13,75 \%$ em 2008, 14,20\% em 2009 e um salto superior a 100\% em 2010. Enquanto isso, os dividendos aumentaram $17,10 \%$ na primeira comparação e tiveram duas reduções de 12,60\% e 44,95\%, nos dois anos seguintes. Os lucros retidos, por sua vez, reduziram 40,94\% em 2008, em 2009 apresentaram um valor de R\$ 1.196.042,00, bem maior que o anterior de $\mathrm{R} \$ 343.044,00$ e em 2010, mantiveram em alta, com 24,03\% a mais sobre esse valor.

As participações dos não-controladores nos anos de 2007 e 2008, demonstraram valores de $\mathrm{R} \$ 5.324, \mathrm{OO}$ e R $\$ 3.122,00$, respectivamente, enquanto em 2009, esse valor reduziu para $\mathrm{R} \$ 138$,00 e em 2010, percebeu-se um valor negativo de -R\$27.739,oo. Enfim, o item "sem descrição" apresentou valor distribuído somente em 2010, nos demais períodos permaneceu zerado.

Seguindo para o segundo mandato presidencial analisado, o setor de Consumo não Cíclico apresentou, em sua grande maioria, percentuais e valores positivos. Logo no primeiro item, percebeu-se um aumento de 80,61\% em 2011 e mesmo com uma queda posterior de 43,83\% no ano seguinte, conseguiu manter-se em alta nos anos de 2013 e 2014, com índices de 99,29\% e 7,21\%, respectivamente. No valor dos dividendos pode-se observar, de 2011 a 2013, percentuais de melhora, em virtude das sucessivas quedas que sofreram, nos dois últimos anos do mandato anterior e em 2014, continuou com um acréscimo de 41,50\%.

O setor de Materiais Básicos apresentou um histórico de evoluções semelhante entre os itens que compõem a Remuneração de Capitais Próprios, durante o período correspondente ao governo Lula. 
Nas comparações feitas nos anos de 2008 e 2009, os quatros principais componentes da distribuição demonstraram queda, com os seguintes percentuais: $23,29 \%$ e 7,05\% nos juros sobre capitais próprios; $10,38 \%$ e $8,02 \%$ nos dividendos; os lucros retidos reduziram $18,99 \%$ e $34,62 \%$ em cada respectivo ano; e as participações dos não-controladores, diminuíram 57,63\% em 2008 e 20,53\% em 2009.

Em 2014, voltaram a se perceber, quedas de $89,51 \%$ nos juros sobre capitais próprios e $63,93 \%$ nos dividendos. Os lucros retidos tiveram em 2011 , acréscimo de $12,33 \%$, mais em seguida caíram 81,95\% e em 2013, seu valor distribuído ficou negativo, em -R \$287.848,oo, ou seja, um provável prejuízo em tal exercício. No último ano de governo, mesmo com uma melhora no valor do item citado anteriormente, este ainda se manteve, muito abaixo da destinação em numerário que apresentava em 2011. As participações dos não-controladores e a subconta "sem descrição" tiveram, durante todo o período desse mandato, valores negativos distribuídos, sendo os maiores percebidos em 2014 no primeiro item, com -R\$975.033,00 e -R\$ 148.897,00 em 2012, no segundo item.

Na Tabela 2, estão contidos dados referentes à distribuição de valor adicionado para Remuneração de Capitais Próprios, dos outros quatro setores econômicos que compõem este estudo: Petróleo, Gás e Biocombustíveis; Tecnologia da Informação; Telecomunicações e Utilidade Pública. Tais valores foram retirados do site da Bovespa, com base nas demonstrações de valor adicionado divulgadas pelas empresas do período de 2007 a 2014, que correspondem ao segundo mandato presidencial de Lula e o primeiro mandato de Dilma. Manteve-se aqui, os percentuais de evolução dos itens que formam este componente da distribuição, para melhor avaliação de seus históricos.

Baseando-se nos dados dispostos na Tabela 2, foi possível observar que o segmento de Petróleo, Gás e Biocombustíveis durante o governo Lula, apresentou evoluções um pouco distintas entre os componentes da distribuição, fazendo-se necessário, o destaque de cada um desses, para melhor compreensão. Assim sendo, os juros sobre capitais próprios demonstraram evoluções positivas de 10,34\% em 2008, 2,50\% apenas em 2009 e em 2010, aumentaram 41,25\% em comparação ao último período. Já os dividendos em 2007 tinham o valor R $\$ 219.352,00$ e

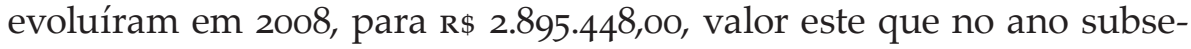
quente, passou por uma redução de 60,61\% e em 2010, demonstrou uma melhora, no entanto, manteve-se inferior a distribuição apresentada em 2008. Os lucros retidos, por sua vez, demonstraram um acréscimo de $54,51 \%$ no ano de 2008 , uma redução de $9,89 \%$ em 2009 e uma melhora de 13,14\% em 2010, voltando praticamente ao mesmo nível de 2008.

As participações dos não-controladores estavam, no primeiro ano de governo, com um valor de $\mathrm{R} \$ 1.742 .826$, o0, no segundo, demonstraram um valor negativo de $-\mathrm{R} \$ 2.089 .497,00$, passando para $\mathrm{R} \$$ 2.752.374, O0 em 2009 e apenas R \$ 700.031,00 em 2010. Referente a este último subitem, Iudícibus et al. (2010) afirmam que se refere a um componente específico da DVA e possui a finalidade de apresentar a parcela de 
valor adicionado destinada aos sócios não controladores. O item "sem descrição" por fim, não apresentou valores durante todo o período do mandato em questão, o que se presume que as empresas, ao divulgar a distribuição de valor adicionado para os Capitais Próprios, detalhou - a corretamente entre tais componentes.

Em sequência, no mandato presidencial de Dilma, o setor de Petróleo, Gás e Biocombustíveis apresentou dados de evoluções e valores ainda mais distintos entre si. Os juros sobre capitais próprios tiveram, por exemplo, acréscimo de 2,69\% em 2011, redução de 14,95\% em 2012, uma pequena melhora a este valor em 2013 e em 2014, não apresentaram valor adicionado distribuído.

Curiosamente, os dividendos em 2011 demonstraram o mesmo valor de 2010, de $\mathrm{R} \$$ 1.565.340,00 e nos demais períodos, apareceram sem valores. Os lucros retidos, por sua vez, passaram por quedas de $11,45 \%$ em 2011 e $42,78 \%$ em 2012 , enquanto no ano seguinte, tiveram uma pequena melhora de $15,99 \%$ em relação ao último valor e em 2014, apresentaram valor negativo, o que se pode deduzir, como um prejuízo apurado no exercício. As participações dos não-controladores em todo período, demonstraram valores negativos, sendo o maior deles, em 2013 com -R\$ 17.998.173,00. O item "sem descrição" permaneceu sem valores distribuídos, durante todo o mandato em análise.

O setor de Tecnologia da Informação, no primeiro mandato presidencial analisado, apresentou históricos diferenciados entre os itens que compõem a Remuneração de Capitais Próprios. Os juros sobre capitais próprios tiveram um acréscimo de 7,92\% em 2008, seguido de uma significativa redução de $61,55 \%$ no ano seguinte e uma melhora em 2010, mesmo assim, fecharam o período com um valor abaixo do que se encontrava em 2007.

Os dados apresentados pelo setor de Tecnologia da Informação, durante o período presidencial de Dilma, ainda foram divergentes entre os itens da análise em relação a valores e percentuais de evolução. Logo em 2011, os juros sobre capitais próprios apresentaram uma melhora de $43,22 \%$ ao valor de 2010 , no entanto no ano seguinte, este valor passou por uma redução de $14,79 \%$ e nos dois períodos posteriores, pode-se dizer que se mantiveram na mesma faixa de valores distribuídos, com um pequeno índice negativo de $0,88 \%$ em 2013 e um positivo de $3,64 \%$ em 2014.

No entanto, notou-se que esses valores, ainda permaneceram inferiores quando comparados aos de 2007 e 2008. Já os dividendos, passaram de $\mathrm{R} \$ 5.115, \mathrm{OO}$ em 2011 para $\mathrm{R} \$ 85.506, \mathrm{OO}$ em $2012 \mathrm{e}$ ainda, em 2013 e 2014, tiveram acréscimos de 40,12\% e 8,66\%. Os lucros retidos, por sua vez, apresentaram queda de 48,11\% em 2011, em 2012 recuperaram-se em $21,68 \%$, ao passo que no ano posterior, seu valor foi de -R\$ 309.626,oo, ou seja, um provável prejuízo apurado no exercício.

Telecomunicações foi um setor econômico que apresentou, durante o mandato de Lula, relevantes variações, tanto em termos monetários quanto em percentuais, nos itens que formam a distribuição 
para Capitais Próprios. Nos anos de 2008 e 2009, notaram-se quedas de $4,76 \%$ e $33,86 \%$ nos juros sobre capitais próprios e nos dividendos também, com 10,23\% e 9,50\% respectivamente. Em 2010, ambos os itens apresentaram melhora, no entanto, os juros sobre capitais próprios continuaram com um valor abaixo do que estavam em 2007 e os dividendos, passaram por um aumento efetivo.

Os lucros retidos aumentaram 65,97\% no ano de 2008 em relação a 2007, sendo que em 2009 notou-se um valor negativo de -R\$ 1.143.666,00, um provável prejuízo apurado em tal exercício e em 2010, o valor divulgado foi de $\mathrm{R} \$ 3.070 .571,00$, bem superior aos demais. As participações dos não-controladores de 2007 para 2008, diminuíram 27,42\%, em 2009 seu valor distribuído foi de - $\mathrm{R} \$ 299.562,00$ e em 2010, passou para $\mathrm{R} \$$ 622.609,00, maior valor do período. O item "sem descrição" não apresentou valores em todo o período presidencial, o que indica um correto detalhamento da distribuição para Capitais Próprios, por parte das empresas deste setor. (TABELA 2)

Adiante no governo Dilma, o setor de Telecomunicações continuou por apresentar um histórico de evoluções bem diferenciadas. Nos juros sobre capitais próprios, logo em 2011, percebeu-se um salto em seu valor, de $94,98 \%$, enquanto no ano seguinte, não tiveram valores distribuídos. Em 2013, este item voltou a apresentar um valor próximo ao de 2011 e ainda, sobre o mesmo, notou-se um acréscimo de $20,37 \%$ em 2014. Os dividendos, por sua vez, tiveram um aumento de $27,94 \%$ em 2011, seguido de três reduções sucessivas de 40,64\% em 2012, 41,40\% em 2013 e $66,72 \%$ em 2014.

De acordo com o CPC o9 (2008) neste subitem, devem constar somente os valores destinados aos sócios e acionistas que tenham como base de cálculo o resultado apurado no período. Assim sendo, presume-se que as reduções apresentadas nos dividendos nos últimos três anos desse mandato no segmento de Telecomunicações, indiquem também uma queda nos lucros desses exercícios. Em seguida, os lucros retidos demonstraram percentuais de evoluções positivos de $6,62 \%$ em 2011 e um bem maior de 77,36\% em 2012, no entanto, em 2013 percebeu-se uma queda $34,47 \%$ e no ano de 2014 , notou-se um valor negativo de -R\$ 894.178,oo, ou seja, um possível prejuízo apurado neste exercício.

As empresas pertencentes ao setor de Utilidade Pública mantiveram, durante o mandato de Lula, a maioria de seus itens de distribuição para Capitais Próprios numa mesma escala, em termos de valores. Os juros sobre capitais próprios tiveram um aumento de 23,26\% em 2008, seguido por duas reduções de $8,52 \%$ e $11,99 \%$ nos dois anos posteriores, mantendo-se próximo ao valor identificado no ano de 2007.

Os dividendos apresentaram um valor maior no primeiro de governo a partir desse, passaram por reduções de 7,59\% em 2008, 0,90\% em 2009 e 2,79\% em 2010. Já os lucros retidos aumentaram 38,43\% em 2008 em relação a 2007, 8,79\% em 2009 e em 2010, reduziu para 2,45\%. As participações dos não-controladores demonstraram oscilações em seu histórico, tendo apresentado os seguintes valores: de R \$601.295,00 


\section{Revista de Gestão Pública}

PRÁTICAS E DESAFIOS

ISSN: 2177-1243

TABela 2 - Distribuição da riqueza para Capital Próprio

\begin{tabular}{|c|c|c|c|c|c|c|c|c|c|c|c|c|c|}
\hline SETOR & GOVERNO & ANO & JuROS S/ C.P. & $\%$ & DIVIDENDOS & $\%$ & $\begin{array}{l}\text { LUCROS } \\
\text { RETIDOS }\end{array}$ & $\%$ & $\begin{array}{c}\text { PART. Ñ } \\
\text { CONTROL. }\end{array}$ & $\%$ & $\begin{array}{c}\text { SEM } \\
\text { DESCRIÇÃo }\end{array}$ & $\%$ & TOTAL CP \\
\hline \multirow{12}{*}{ 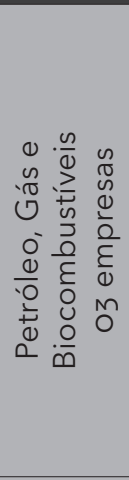 } & \multirow{4}{*}{$\begin{array}{c}\text { Governo } \\
\text { Lula }\end{array}$} & 2007 & $6.361 .205,00$ & - & $219.352,00$ & - & $14.917 .097,00$ & - & $1.742 .826, \mathrm{oO}$ & - & $0, \mathrm{OO}^{3}$ & - & $23.240 .480,00$ \\
\hline & & 2008 & 7.019.261,00 & 10,34 & $2.895 \cdot 448,00$ & $1.220,00$ & $23.048 .100,00$ & 54,51 & $-2.089 .497,00$ & $-219,89$ & $\mathrm{O}, \mathrm{OO}$ & 0,00 & $30.873 .312,00$ \\
\hline & & 2009 & $7.194 .743,00$ & 2,50 & $1.140 .630,00$ & $-60,61$ & $20.768 .495,00$ & $-9,89$ & $2.752 .374, \mathrm{OO}$ & $-231,72$ & $\mathrm{O}, \mathrm{OO}$ & 0,00 & $31.856 .242,00$ \\
\hline & & 2010 & $10.162 .324,00$ & 41,25 & $1.565 .340,00$ & 37,23 & $23 \cdot 497 \cdot 275, \mathrm{oO}$ & 13,14 & $700.031,00$ & $-74,57$ & 0,00 & 0,00 & $35.924 .970,00$ \\
\hline & \multicolumn{2}{|l|}{$\% 2007 / 2010$} & & 59,75 & & 613,62 & & 57,52 & & $-59,83$ & & 0,00 & \\
\hline & \multicolumn{2}{|l|}{ Subtotal } & $30.737 .533,00$ & & $5.820 .770,00$ & & $82.230 .967,00$ & & $3.105 .734,00$ & & 0,00 & & $121.895 .004,00$ \\
\hline & \multirow{4}{*}{$\begin{array}{l}\text { Governo } \\
\text { Dilma }\end{array}$} & 2011 & $10.435 .598, \mathrm{oO}$ & 2,69 & $1.565 .340,00$ & $\mathrm{O}, \mathrm{OO}$ & $20.807 .858,00$ & $-11,45$ & $-231.205,00$ & $-133,03$ & 0,00 & 0,00 & $32.577 .591,00$ \\
\hline & & 2012 & $8.875 .915,00$ & $-14,95$ & 0,00 & $-100,00$ & $11.905 .610,00$ & $-42,78$ & $-1.361 .745,00$ & 488,98 & 0,00 & 0,00 & $19.419 .780,00$ \\
\hline & & 2013 & 9.301.024,00 & 4,79 & 0,00 & $0, \mathrm{OO}$ & $13.809 .604,00$ & 15,99 & $-17.998 .173,00$ & $1.221,70$ & 0,00 & 0,00 & $5.112 .455,00$ \\
\hline & & 2014 & 0,00 & $-100,00$ & 0,00 & 0,00 & - 11.904.794,00 & $-186,21$ & $-337.000,00$ & $-98,13$ & 0,00 & 0,00 & $-12.241 .794,00$ \\
\hline & \multicolumn{2}{|c|}{$\% 2011 / 2014$} & & $-100,00$ & & $-100,00$ & & $-157,21$ & & 45,76 & & 0,00 & \\
\hline & \multicolumn{2}{|l|}{ Subtotal } & $28.612 .537,00$ & & $1.565 .340,00$ & & $34.618 .278, \mathrm{oo}$ & & $-19.928 .123,00$ & & 0,00 & & $44.868 .032,00$ \\
\hline \multirow{12}{*}{ 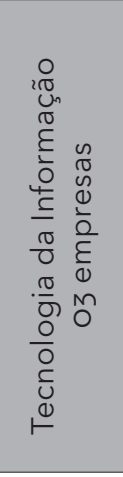 } & \multirow{4}{*}{$\begin{array}{l}\text { Governo } \\
\text { Lula }\end{array}$} & 2007 & $54.223,00$ & - & $34.242,00$ & - & $147 \cdot 544,00$ & - & 413,00 & - & 0,00 & - & $236.422,00$ \\
\hline & & 2008 & $58.515,00$ & 7,92 & $52.670,00$ & 53,82 & $176.934,00$ & 19,92 & $1.317,00$ & 218,89 & 0,00 & 0,00 & $289.436,00$ \\
\hline & & 2009 & $22.500,00$ & $-61,55$ & $112.412,00$ & 113,43 & $157.670,00$ & $-10,89$ & $2.602,00$ & 97,57 & 0,00 & 0,00 & $295.184,00$ \\
\hline & & 2010 & $32.942,00$ & 46,41 & $28.121,00$ & $-74,98$ & $177.850,00$ & 12,80 & $-335,00$ & $-112,87$ & 0,00 & 0,00 & $238.578, \mathrm{oO}$ \\
\hline & \multicolumn{2}{|c|}{$\% 2007 / 2010$} & & $-39,25$ & & $-17,88$ & & 20,54 & & $-181,11$ & & 0,00 & \\
\hline & \multicolumn{2}{|l|}{ Subtotal } & $168.180,00$ & & $227.445,00$ & & $659.998,00$ & & $3.997,00$ & & 0,00 & & $1.059 .620,00$ \\
\hline & \multirow{4}{*}{$\begin{array}{l}\text { Governo } \\
\text { Dilma }\end{array}$} & 2011 & $47.179,00$ & 43,22 & $5.115,00$ & $-81,81$ & $92.290,00$ & $-48,11$ & 480,00 & $-243,28$ & $\mathrm{O}, \mathrm{OO}$ & 0,00 & $145.064,00$ \\
\hline & & 2012 & $40.200,00$ & $-14,79$ & $85.506,00$ & $1.571,67$ & $112.294,00$ & 21,68 & 838,00 & 74,58 & 0,00 & 0,00 & $238.838,00$ \\
\hline & & 2013 & $39.845,00$ & $-0,88$ & $119.812,00$ & 40,12 & $-309.626,00$ & $-375,73$ & $-17,00$ & $-102,03$ & 0,00 & 0,00 & $-149.986,00$ \\
\hline & & 2014 & $41.295,00$ & 3,64 & $130.185,00$ & 8,66 & $76.089,00$ & $-124,57$ & $-172,00$ & 911,76 & 0,00 & 0,00 & $247.397,00$ \\
\hline & \multicolumn{2}{|c|}{$\% 2011 / 2014$} & & $-12,47$ & & $2.445,16$ & & $-17,55$ & & $-135,83$ & & 0,00 & \\
\hline & \multicolumn{2}{|l|}{ Subtotal } & $168.519,00$ & & $340.618,00$ & & $-28.953,00$ & & $1.129,00$ & & 0,00 & & $481.313,00$ \\
\hline
\end{tabular}




\section{Revista de Gestão Pública}

PRÁTICAS E DESAFIOS

ISSN: 2177-1243

\begin{tabular}{|c|c|c|c|c|c|c|c|c|c|c|c|c|c|}
\hline \multirow{12}{*}{ 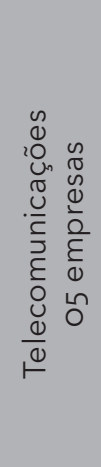 } & \multirow{4}{*}{$\begin{array}{l}\text { Governo } \\
\text { Lula }\end{array}$} & 2007 & $1.039 .775,00$ & - & $2.200 .273,00$ & - & $410.074,00$ & - & $501.754,00$ & - & 0,00 & - & $4.151 .876,00$ \\
\hline & & 2008 & $990.303,00$ & $-4,76$ & $1.975 .115,00$ & $-10,23$ & $680.589,00$ & 65,97 & $364.171,00$ & $-27,42$ & 0,00 & 0,00 & 4.010.178,00 \\
\hline & & 2009 & $655.000,00$ & $-33,86$ & $1.787 .446,00$ & $-9,50$ & $-1.143 .666,00$ & $-268,04$ & $-299.562,00$ & $-182,26$ & 0,00 & 0,00 & $999.218,00$ \\
\hline & & 2010 & $957.519,00$ & 46,19 & $2.479 .929,00$ & 38,74 & 3.070.571,00 & $-368,48$ & $622.609,00$ & $-307,84$ & 0,00 & 0,00 & $7.130 .628,00$ \\
\hline & \multicolumn{2}{|c|}{$\% 2007 / 2010$} & & $-7,91$ & & 12,71 & & 648,78 & & 24,09 & & 0,00 & \\
\hline & \multicolumn{2}{|l|}{ Subtotal } & $3.642 .597,00$ & & $8.442 .763,00$ & & $3.017 .568,00$ & & $1.188 .972,00$ & & 0,00 & & $16.291 .900,00$ \\
\hline & \multirow{4}{*}{$\begin{array}{l}\text { Governo } \\
\text { Dilma }\end{array}$} & 2011 & $1.867 .000,00$ & 94,98 & $3.172 .816,00$ & 27,94 & $3.273 .806,00$ & 6,62 & $163.499,00$ & $-73,74$ & 0,00 & 0,00 & $8.477 .121,00$ \\
\hline & & 2012 & 0,00 & $-100,00$ & $1.883 .319, \mathrm{oO}$ & $-40,64$ & $5.806 .547,00$ & 77,36 & $205.366,00$ & 25,61 & 0,00 & 0,00 & $7.895 .232,00$ \\
\hline & & 2013 & $1.738 .000,00$ & $\mathrm{O}, \mathrm{OO}$ & $1.103 .583,00$ & $-41,40$ & $3.804 .860,00$ & $-34,47$ & $66.653,00$ & $-67,54$ & 0,00 & 0,00 & $6.713 .096,00$ \\
\hline & & 2014 & 2.092.000,00 & 20,37 & $367.274,00$ & $-66,72$ & $-894.178,00$ & $-123,50$ & $-390.454,00$ & $-685,80$ & 0,00 & 0,00 & $1.174 .642,00$ \\
\hline & \multicolumn{2}{|c|}{$\% 2011 / 2014$} & & 12,05 & & $-88,42$ & & $-127,31$ & & $-338,81$ & & 0,00 & \\
\hline & \multicolumn{2}{|l|}{ Subtotal } & $5.697 .000,00$ & & $6.526 .992,00$ & & $11.991 .035,00$ & & $45.064,00$ & & $0, \mathrm{OO}$ & & $24.260 .091,00$ \\
\hline \multirow{12}{*}{ 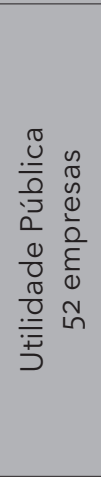 } & \multirow{4}{*}{$\begin{array}{l}\text { Governo } \\
\text { Lula }\end{array}$} & 2007 & $4.172 .402,00$ & - & $10.350 .176,00$ & - & $6.345 .210,00$ & - & $601.295,00$ & - & 0,00 & - & $21.469 .083,00$ \\
\hline & & 2008 & $5.142 .864,00$ & 23,26 & $9.565 .000,00$ & $-7,59$ & $8.783 .919,00$ & 38,43 & $1.008 .114,00$ & 67,66 & 0,00 & 0,00 & $24.499 .897,00$ \\
\hline & & 2009 & $4.704 .940,00$ & $-8,52$ & $9 \cdot 479 \cdot 392,00$ & $-0,90$ & $9.556 .289,00$ & 8,79 & $876.298,00$ & $-13,08$ & 0,00 & 0,00 & $24.616 .919,00$ \\
\hline & & 2010 & $4.140 .603,00$ & $-11,99$ & 9.215.171, $\mathrm{OO}$ & $-2,79$ & $9.322 .333,00$ & $-2,45$ & $2.490 .757,00$ & 184,24 & $599.715,00$ & 0,00 & $25.768 .579,00$ \\
\hline & \multicolumn{2}{|c|}{$\% 2007 / 2010$} & & $-0,76$ & & $-10,97$ & & 46,92 & & 314,23 & & 0,00 & \\
\hline & \multicolumn{2}{|l|}{ Subtotal } & $18.160 .809,00$ & & $38.609 .739,00$ & & $34.007 .751,00$ & & $4.976 .464,00$ & & $599.715,00$ & & $96.354 .478, \mathrm{oo}$ \\
\hline & \multirow{4}{*}{$\begin{array}{l}\text { Governo } \\
\text { Dilma }\end{array}$} & 2011 & $4.656 .804,00$ & 12,47 & $9.780 .996,00$ & 6,14 & $12.031 .447,00$ & 29,06 & $3.210 .122,00$ & 28,88 & $\mathrm{O}, \mathrm{OO}$ & $-100,00$ & $29.679 .369,00$ \\
\hline & & 2012 & $5.041 .814,00$ & 8,27 & $7.613 .737,00$ & $-22,16$ & $-1.075 .417,00$ & $-108,94$ & $829.743,00$ & $-74,15$ & 0,00 & $\mathrm{O}, \mathrm{OO}$ & $12.409 .877,00$ \\
\hline & & 2013 & $3.593 .360,00$ & $-28,73$ & $7.100 .944,00$ & $-6,74$ & $268.712, \mathrm{OO}$ & $-124,99$ & 1.093.100,00 & 31,74 & 0,00 & 0,00 & $12.056 .116,00$ \\
\hline & & 2014 & $2.330 .871,00$ & $-35,13$ & 7.006.709,00 & $-1,33$ & $6.881 .264,00$ & $2.460,83$ & $639.687,00$ & $-41,48$ & 0,00 & $\mathrm{O}, \mathrm{OO}$ & $16.858 .531,00$ \\
\hline & \multicolumn{2}{|c|}{$\% 2011 / 2014$} & & $-49,95$ & & $-28,36$ & & $-42,81$ & & $-80,07$ & & 0,00 & \\
\hline & \multicolumn{2}{|l|}{ Subtotal } & $15.622 .849,00$ & & $31.502 .386,00$ & & 18.106.006,00 & & $5.772 .652,00$ & & 0,00 & & $71.003 .893,00$ \\
\hline
\end{tabular}

FONTE: Elaborado pela autora. 
em 2007, passaram para $\mathrm{R} \$ 1.008 .114,00$ em 2008, este valor reduziu para $\mathrm{R} \$ 876.298$,00 em 2009 e em 2010, demonstraram como valor distribuído R\$2.490.757,00. A subconta "sem descrição" teve distribuição de valor, apenas em 2010 com $\mathrm{R} \$$ 599.715,00, o restante do período permaneceu zerada.

No governo Dilma, o setor de Utilidade Pública apresentou melhoras nos juros sobre capitais próprios, com 12,47\% em 2011 e 8,27\% em 2012, no entanto em 2013 e 2014, voltaram a reduzir, com índices negativos de $28,73 \%$ e $35,13 \%$, respectivamente. Resultado similar ocorreu com os dividendos que, em 2011 demonstrou um pequeno acréscimo de 6,14\%, como um índice de recuperação, no entanto nos três períodos seguintes, voltaram a apresentar reduções de 22,16\% em 2012, 6,74\% em 2013 e $1,33 \%$ em 2014.

Os lucros retidos demonstraram valores discrepantes em todo o período desse mandato: em 2011 apresentaram um salto no valor em relação aos do governo anterior, com R \$12.031.447,00, já em 2012, percebeu-se um valor negativo de -R \$ 1.075.417,00, ou seja, um provável prejuízo do exercício, seguindo para 2013 e 2014, os valores distribuídos foram de $\mathrm{R} \$ 268.712$, O0 e $\mathrm{R} \$ 6.881 .264$, 00 .

As participações dos não-controladores em 2011 tiveram, um acréscimo de 28,88\% em relação ao último valor apresentado em 2010, no entanto diminuíram 74,15\% no ano seguinte, em 2013 tiveram uma pequena melhora e em 2014, voltaram a cair. Em suma, todos os quatros itens terminaram o período presidencial, com valores menores que em seu início. Lembrando que, o item "sem descrição" permaneceu durante todo mandato, sem valores distribuídos.

\section{CONSIDERAÇÕES FINAIS}

Por meio da DVA, o estudo teve como objetivo analisar a evolução da riqueza setorial gerada pelas empresas listadas na BM\&FBovespa e distribuída ao seus sócios e acionistas, considerando os mandatos presidenciais de Lula (2007-2010) e Dilma (2011-2014). Assim, podem-se constatar divergências nas evoluções da remuneração de capitais próprios de um mandato presidencial para outro.

Considerando inicialmente o mandato presidencial de Lula, pode-se perceber que cada segmento apresentou alguma particularidade relevante na distribuição de riqueza. No setor de Bens Industriais, por exemplo, o maior valor distribuído foi identificado em 2008 e pode-se perceber que os componentes que contribuíram para este resultado, foram os juros sobre capital próprio, os dividendos e os lucros retidos.

Observou-se que as empresas de Construção e Transporte, somente no ano de 2009 demonstraram valor de distribuição positivo, assim como somente neste período, que os lucros retidos também tiveram valores positivos. Nos demais anos deste setor, tanto os lucros retidos, neste caso prováveis prejuízos apurados, quanto o total desti- 
nado aos Capitais Próprios, tiveram valores de distribuição negativos. Já no Consumo não Cíclico, pode-se notar que estes itens foram os juros sobre capitais próprios, lucros retidos e a subconta "sem descrição", enquanto no segmento de Materiais Básicos, a parcela de maior contribuição foi dos lucros retidos.

Ainda considerando o período presidencial de Lula, pode-se notar que os segmentos de Petróleo, Gás e Biocombustíveis, Telecomunicações e Utilidade Pública tiveram seus maiores valores distribuídos no último ano do governo analisado, ou seja, em 2010. O setor de Tecnologia da Informação, no entanto, teve sua maior distribuição para Capitais Próprios no ano de 2009 e os itens que proporcionaram tal feito, foram os dividendos e as participações dos não-controladores.

Posteriormente, durante o governo Dilma, também se perceberam alguns pontos significativos em cada setor econômico, em relação à distribuição para Capitais Próprios. Os setores de Bens Industriais e Construção e Transporte tiveram seus maiores valores distribuídos no ano de 2013, ambos com faixas menores do que as maiores destinações no governo anteriormente analisado. Vale destacar, que neste primeiro setor, os itens que ajudaram a alcançar este resultado, foram os lucros retidos, as participações dos não-controladores e o item "sem descrição". Já no segundo setor citado, pode-se notar que os quatros principais componentes da distribuição tiveram aumentos relevantes que favoreceram tal posição, no entanto, este mesmo período foi o único que apresentou valor positivo nos lucros retidos, nos demais se percebeu prováveis prejuízos apurados nos exercícios. Isto acabou afetando os valores de distribuição dos anos de 2011, 2012 e 2014, sendo bem menores em relação a 2013.

O setor de Materiais Básicos apresentou o seu maior valor distribuído no ano de 2011, por consequência do aumento nos lucros retidos. Ainda sobre este ramo, pode-se observar que nos períodos subsequentes, esta distribuição caiu consideravelmente, assim como os lucros retidos, inclusive com períodos de prejuízos apurados. Além disso, as participações dos não-controladores e o item "sem descrição" apresentaram valores negativos em todo o período presidencial. Estas duas causas aliadas, contribuíram de certa forma, para a queda da Remuneração de Capitais Próprios neste segmento.

Outros dois setores, Telecomunicações e Utilidade Pública que, apesar de também passarem por reduções posteriores em suas evoluções, apresentaram aumentos efetivos em 2011 em relação a 2010, ano com maior distribuição do governo Lula. Vale destacar que, em Telecomunicações, os itens que mais contribuíram para tal acréscimo foram os juros sobre capitais próprios e os dividendos, enquanto em Utilidade Pública foram os lucros retidos e as participações dos não-controladores.

A fim de dar continuidade ao tema abordado nesta pesquisa, sugere-se para pesquisas futuras, a busca por variáveis macroeconômicas e financeiras que possam explicar e justificar as evoluções identificadas 
na distribuição de 1valor adicionado aos sócios e acionistas, na forma de remuneração de capitais próprios. Do mesmo modo, recomenda-se replicar o objetivo deste estudo em mandatos presidenciais subsequentes, afim de, avaliar as evoluções identificadas nesta pesquisa em comparação com as posteriores.

\section{REFERÊNCIAS}

ALVES, J. F. V; OLIVEIRA, M. C. A evolução da evidenciação da demonstração do valor adicionado no Brasil e a geração e distribuição de riqueza por empresas brasileiras. In: CONGRESSO USP DE CONTROLADORIA E CONTABILIDADE, 17., 2003. São Paulo. Anais... São Paulo, 2003.

BORINELLI, M. L.; PIMENTEL, R. C. Curso de Contabilidade para gestores, analistas e outros profissionais. São Paulo: Atlas, 2010.

COSTA, C. L. O., GUIMARÃES, T. R.; MELLO, L. C. B. B. Os possíveis benefícios gerados pela obrigatoriedade da publicação da Demonstração do Valor Adicionado pelas empresas de capital aberto. Revista de Contabilidade do Mestrado em Ciências Contábeis da UERJ, v. 18, n. 3, p. 77-93, 2013.

COSTA, C. L. O.; GUIMARÃES, T. R.; MELLO, L. C. B. B. Os possíveis benefícios gerados pela obrigatoriedade da publicação da demonstração do valor adicionado pelas empresas de capital aberto. Revista de Contabilidade do Mestrado em Ciências Contábeis da UERJ, v. 18, n. 3, p. 77-93, 2013.

COSENZA, José Paulo. A eficácia informativa da demonstração do valor adicionado. Revista Contabilidade \& Finanças, v. 14, n. SPE, p. 07-29, 2003.

CUNHA, J. V. A.; RIBEIRO, M. S.; SANTOS, A. A demonstração do valor adicionado como instrumento de mensuração da distribuição da riqueza. Revista Contabilidade \& Finanças, v. 16, n. 37, p. 7-23, 2005.

FAGUNDES, J. A. et al. A demonstração do valor adicionado DVA como fonte de informações gerenciais: um estudo em uma cooperativa de crédito. ABCustos, v. 3, n. 1, 2015.

FOLLMANN, D. A.; PAIVA, K. S. E.; SOARES, S. V. Distribuição do valor adicionado nas empresas do Novo Mercado: análise setorial da destinação da riqueza em 2008 e 2009. Revista Reunir, v. 1, n. 2, p. 101-117, 2015.

IUDÍCIBUS, S. Análise de balanço. 10. ed. São Paulo: Atlas 2010.

QUINTEIRO, L. G. L. A relação entre a evidenciação de informações contábeis e a volatilidade dos retornos das ações no Brasil. Anais República Dominicana: CLADEA, 2004.

RICARTE, J. G. Demonstração do valor adicionado. Revista Catarinense da Ciência Contábil, Florianópolis, 2005. 
SANTOS, A. Demonstração do valor adicionado: como elaborar e analisar a DVA. 2. Ed. São Paulo: Atlas, 2007.

SILVA, E. M. A relevância da Demonstração do Valor Adicionado na evidenciação da distribuição da riqueza: um estudo da DVA na crise de 2008-2009. 2010. Dissertação (Mestrado) Pontifícia Universidade Católica de São Paulo, São Paulo.

SANTOS, A. et al. A economia das empresas nos governos FHC e Lula: uma análise a partir da Demonstração do Valor Adicionado. Revista Contabilidade e Controladoria, v. 5, n. 1, 2013.

SILVA, A. H. C. et al. Demonstração do Valor Adicionado (DVA): Uma análise de sua comparabilidade após tornar-se obrigatória no Brasil. Revista de Contabilidade do Mestrado em Ciências Contábeis da UERJ, v. 19, n. 1, p. 95-110, 2014.

VERRECCHIA, R. E. Essays on disclosure. Journal of accounting and economics, v. 32, n. 1, p. 97-180, 2001.

VIEIRA, E. J. et al. Um comparativo de quocientes de valor adicionado: o caso de um banco comercial. 2009. 